\title{
Genetic Polymorphisms of Mitochondrial Genome D-loop Region in Bakhtiarian Population by PCR-RFLP
}

\author{
Abbas Doosti (Corresponding author) \\ Biotechnology Research Center, Islamic Azad University \\ Shahrekord Branch, Shahrekord, PO box 166, Iran \\ Tel: 98-381-336-1001Ｅ-mail: biologyshki@yahoo.com \\ Payam Ghasemi Dehkordi \\ Biotechnology Research Center, Islamic Azad University \\ Shahrekord Branch, Shahrekord, PO box 166, Iran \\ Tel: 98-381-336-1001Ｅ-mail: payamghasemidehkordi@yahoo.com
}

Received: June 14, 2011 Accepted: July 1, 2011 doi:10.5539/ijb.v3n4p41

\begin{abstract}
The human mitochondrial DNA is a 16569 bp closed, circular molecule that was sequenced and mapped. The Dloop of mitochondrial DNA is a major control site for mtDNA expression and it is important in maternal inheritance. This region in different population is vary and contains essential transcription and replication elements and it could be used for detection of mother inheritance, and human evolution. The aim of present study was to determine the D-loop region polymorphism in Bakhtiarian population in southwest Iran. The blood samples of 168 healthy people of Bakhtiarian population in Iran were collected and total DNA was extracted and then, mtDNA D-loop region was amplified by PCR using specific primers. Restriction fragment length polymorphism (RFLP) was analyzed in PCR products by HaeIII and AluI restriction endonuclease. Amplified fragments for mtDNA D-loop region on 1\% agarose gel revealed a fragment of about $1024 \mathrm{bp}$. The results of this study showed 5 restriction patterns for HaeIII enzyme (with 1 heteroplasmy) and 2 restriction patterns for AluI enzyme (with 2 heteroplasmies) in Bakhtiarian population. The findings showed a low level of genetic polymorphism in D-loop region and it is related to high kinship marriages and low range of migration in Bakhtiarian population.
\end{abstract}

Keywords: mtDNA, D-loop region, RFLP, Polymorphism, Bakhtiarian population, Iran

\section{Introduction}

The human mitochondrial DNA (mtDNA) is a circular double-stranded molecule, and was first fully sequenced in 1981 by Anderson et al. (Hoong \& Lek, 2005). Most human cells contain hundreds of mitochondria and thousands of mitochondrial DNA copies (Wallace, 1994). mtDNA have 16,569 base pairs in length that codes for 13 subunits of the oxidative phosphorylation system, 2 ribosomal RNAs (rRNAs), and 22 transfer RNAs (tRNAs) (Hoong \& Lek, 2005; Ketmaier \& Bernardini, 2005). mtDNA is present in high copy number in human cells, with high mutation rate, haplogroup, without recombination and maternal inheritance (Sbisa et al., 1997; Tsutsumi et al., 2006). These specifications make mtDNA easier to obtain for analysis, and also make it the molecule of choice for analyzing ancient DNA and for certain forensic DNA applications (Witas \& Zawicki, 2004; Tsutsumi et al., 2006).

The Displacement loop (D-loop) occurs in the main non-coding area of the mitochondrial DNA molecule, a segment called the control region or D-loop region (Pereira et al., 2004). The D-loop is the location of mitochondrial transcription promoters and it is the major control site for mtDNA expression because it contains the leading-strand for origin of replication and major promoters for transcription (Miyazono et al., 2002). mtDNA replication begins in the D-loop resulting in the formation of a displacement loop with a newly synthesized heavy, or H, strand of about 700nt known as 7S DNA (Sbisa et al., 1997). Both strands of the mtDNA are completely transcribed from the promoters in the D-loop. In addition to the promoter sequences, there are two small regions known as the hypervariable regions I and II (HVI and HVII). Mutation rates in HVI 
and HVII are especially high on average and there is evidence that the rates vary within the regions as well (Jazin et al., 1998). mtDNA analysis has been focused mainly on the HVI and the correlation between the HVI and HVII regions has not been well established (Salas et al., 2001).

This greater polymorphic rate in the D-loop region has been reported in humans and polymorphism patterns of this region are variable in human population of Iran. The purpose of present study was to determine the polymorphism patterns of D-loop region using PCR-RFLP techniques in Bakhtiarian population in southwest Iran.

\section{Materials and methods}

\subsection{Samples collection and DNA extraction}

Blood samples of 168 healthy people ( 87 men and 81 women) in Bakhtiarian population were collected randomly. Samples were obtained at five locations (Farsan, Lordegan, Gahrou, Ardal, and Kouhrang) located in southwest Iran (Chahrmahal Va Bakhtiari province). Whole genomic DNA contain mtDNA was extracted from blood using the Qiagen DNA extraction kit (Qiagen, Hilden, Germany) according to the manufacturer's recommendation.

The extracted genomic DNA was quantified by spectrophotometric measurement at a wavelength of $260 \mathrm{~nm}$ according to the method described by Sambrook and Russell (Sambrook \& Russell, 2001).

\subsection{PCR amplification of the mtDNA D-loop region}

The mtDNA D-loop region was amplified by PCR using primers Mt-F (5'- CACCATTAGCACCCAAAGCT$3^{\prime}$ ) and Mt-R (5'-CTGTTAAAAGTGCATACCGCCA-3') with accession number NC012920.1 as described by Salas for HVI region (Salas et al., 2001). Polymerase chain reaction (PCR) was carried out in $25 \mu 1$ total reaction volumes, each containing $100 \mathrm{ng}$ of template DNA, $0.2 \mathrm{pM}$ of each primer, $2.5 \mu 1$ of 10X PCR buffer, $1.5 \mathrm{mM}$ $\mathrm{MgCl}_{2}, 200 \mathrm{mM}$ dNTPs, and 1 unit of Taq DNA polymerase (Fermentas, Germany). The reaction mixture was heated to $94^{\circ} \mathrm{C}$ for 5 minutes, followed by 30 cycles each consisting of 1 min denaturation at $94^{\circ} \mathrm{C}, 1 \mathrm{~min}$ annealing at $60^{\circ} \mathrm{C}, 1 \mathrm{~min}$ of extension at $72^{\circ} \mathrm{C}$ and a final 5 min extension at $72^{\circ} \mathrm{C}$. The PCR amplification products $(10 \mu \mathrm{l})$ were subjected to electrophoresis in a $1 \%$ agarose gel in $1 \mathrm{X}$ TBE buffer at $80 \mathrm{~V}$ for $30 \mathrm{~min}$, stained with Ethidium Bromide, and images were obtained in UVIdoc gel documentation systems (UK).

\section{3 mtDNA D-loop region polymorphism}

Restriction fragment length polymorphisms (RFLPs) were used for analysis of mtDNA D-loop sequence polymorphisms. PCR products were digested with HaeIII and AluI (Roche applied science) in a total volume of $20 \mu \mathrm{l}(10 \mu \mathrm{l}$ reaction solutions, $2 \mu \mathrm{l}$ enzyme buffers, $0.2 \mu \mathrm{l}$ enzymes, and $7.8 \mu \mathrm{l}$ distilled water) and placed in the incubator at $37^{\circ} \mathrm{C}$ for 4 hours. The restriction products were analyzed by electrophoresis on a $2 \%$ agarose gel and molecular weight of restricted fragments analyzed by UVIdoc 1D software in UVIdoc gel documentation systems (UK) after Ethidium Bromide staining.

\subsection{Statistical analysis}

Analysis of polymorphic patterns in Bakhtiarian population was performed using the SPSS version 17.0 computer software (SPSS, Chicago, IL). Also, differences and comparison between mtDNA D-loop region polymorphism in Bakhtiarian population and other previous studies on this region in the world were examined by $\mathrm{T}$ test statistical analysis. $\mathrm{P}$ values $<0.05$ were considered significant.

\section{Results}

PCR-RFLP techniques were used to reveal polymorphism of mtDNA D-loop region in Bakhtiarian population. PCR products for mtDNA D-loop region on agarose gel showed a fragment of about $1024 \mathrm{bp}$. Digestion of amplified fragments of mtDNA D-loop region by HaeIII and AluI restriction endonuclease and their frequency are listed in tables 1 and 2. The restriction enzymes, HaeIII and AluI, presented polymorphism in figures 1 and 2.

The results showed 5 restriction patterns for HaeIII enzyme (with 1 heteroplasmy) and 2 restriction patterns for AluI enzyme (with 2 heteroplasmy) in Bakhtiarian population. The fragments at 35, 109, 365, 400, 405, 435, 480, 510, and 550 bps were related to HaeIII enzyme (Table 1 and Figure 1) and fragments at 100, 124, 400, 500 , and 800 bps were related to AluI enzyme (Table 2 and Figure 2). The results of this study showed low level of heteroplasmy and polymorphic patterns for mtDNA D-loop region in Bakhtiarian population. The findings of present study were compared to other human studies for this gene on other population of the world and showed significant relationship between findings ( $\mathrm{P}$ values $<0.05$ ). 


\section{Discussion}

The properties of mtDNA D-loop that make it valuable for both evolutionary and human identification studies include the high copy number, cytoplasmic inheritance, and rapid rate of evolution (Miyazono et al., 2002; Pereira et al., 2010). The mutation rate of mtDNA is several orders of magnitude higher than that of nuclear genes, with an estimated rate of 1.7 times $10^{-8}$ substitutions per site per year for the whole genome excluding the control region (Ingman et al., 2000). Tracing migrations of Homo sapiens with the help of mtDNA is based on the observation that the occurrence of certain haplotypes is often associated with certain world regions and the assumption that this is a result of accumulation of various mutations in different maternal lineages that occurred as people migrated and inhabited new regions (Tiedemann et al., 2000).

Many other methods of studying mtDNA recently applied, such as RFLP analysis and direct sequencing; enable more precise calculations to be made. A number of techniques, developed in the last few decades have greatly contributed to the methodology used, with the most pronounced ones, such as PCR based methods that allowed the copying of even minute amount of the sequence of interest (Hoong \& Lek, 2005).

In present study PCR-RFLP techniques were used to reveal polymorphism of mtDNA D-loop region in Bakhtiarian population of Iran. The results were showed 5 restriction patterns for HaeIII enzyme and 2 restriction patterns for AluI enzyme with 1 and 2 heteroplasmy, respectively. The results showed that low heteroplasmy and polymorphic patterns for mtDNA D-loop region after digestion with these enzymes in this population.

Historically, Bakhtiari tribe one of the purest human race are living in Iran. In Bakhtiarian population ethnic prejudice is very high and kinship marriages greatly occurred between them. Furthermore, Bakhtiari tribe live in a closed geographical area and have a little and limited communication with other parts of the country and these conditions confirmed the low level of heteroplasmy and polymorphic patterns for mtDNA D-loop region that observed in this population. These specifications are could be used in human population studies and forensic investigations in Bakhtiarian population.

In recent years there are many much research on mtDNA D-loop polymorphism were done. Horai et al. were studied on mtDNA polymorphism in East Asian populations, with special reference to the peopling of Japan in 1996 and their findings were showed compatible with the hybridization model on the origin of modern Japanese (Horai et al., 1996). The study of Hoong and Lek in 2005 on genetic polymorphisms in mitochondrial DNA hypervariable regions I, II and III of the Malaysian population showed that these regions of mtDNA could be used in forensic investigations, complement anthropology and population studies in Asia (Hoong \& Lek, 2005). The results of their study confirmed the findings of current research. Barbosa et al. in 2008 were determined sequences of the two hypervariable (HV) segments of the mtDNA control region in the state of Alagoas, northeastern Brazil. The results of their study showed mitochondrial control region is importance for forensic casework and population studies in this region and confirmed the findings of present study in Bakhtiarian population (Barbosa et al., 2008). The analysis of the genetic structure of the Kazakh population as estimated from mitochondrial DNA polymorphism showed that Western Europe (55\%) and Eastern Europe (41\%) mtDNA lineages exist in the Kazakhs population and high genetic diversity was observed in the Kazakhs population (Berezina et al., 2011).

The above findings indicated that D-loop region of human mtDNA variability, as detected by the number of different RFLP morphs, is useful for detection of maternal inheritance, forensic casework and human evolution. Our results are consistent to the facts that low levels of variability in mtDNA D-loop region in Bakhtiarian population of Iran. Characteristics and conditions such as ethnic prejudice, existence of traditional rural area and lack of the appropriate roads in southwest Iran with other parts of the country that cause high level of kinship marriages and low migration in Bakhtiarian population and suitable this people for human population studies and forensic investigations in future.

\section{Acknowledgements}

The authors would like to express their deep and sincere gratitude to the staff of Biotechnology Research Center of Islamic Azad University of Shahrekord Branch in southwest Iran.

\section{References}

Barbosa, A.B.G., da Silva, L.A.F., Azevedo, D.A, Balbino, V.Q. \& Mauricio-da-Silva, L. (2008). Mitochondrial DNA control region polymorphism in the population of Alagoas state, north-eastern Brazil. Journal of Forensic Sciences, 51(3): 142-146. http://dx.doi.org/10.1111/j.1556-4029.2007.00619.x 
Berezina, G., Svyatova, G. \& Makhmutova, Z. (2011). The analysis of the genetic structure of the Kazakh population as estimated from mitochondrial DNA polymorphism. Medical and Health Science Journal, 6: 2-6.

Hoong, L.L. \& Lek, K.C. (2005). Genetic polymorphisms in mitochondrial DNA hypervariable regions I, II and III of the Malaysian population. Asia-Pacific Journal of Molecular Biology and Biotechnology, 13(2): 79-85.

Horai, S., Murayama, K., Hayasaka, K., Matsubayashi, S., Hattori, Y., Fucharoen, G., Harihara, S., Park, K.S., Omoto, K. \& Pan, I.H. (1996). mtDNA polymorphism in East Asian Populations, with special reference to the peopling of Japan. American Journal of Human Genetics, 59(3): 579-590.

Ingman, M., Kaessmann, H., Paabo, S. \& Gyllensten, U. (2000). Mitochondrial genome variation and the origin of modern humans. Nature, 408, 708-713. http://dx.doi.org/10.1038/35047064

Jazin, E., Soodyall, H., Jalonen, P., Lindholm, E., Stoneking, M. \& Gyllensten, U. (1998). Mitochondrial mutation rate revisited: hot spots and polymorphism. Nature Genetics, 18: 109-110. http://dx.doi.org/10.1038/ng0298-109

Ketmaier, V. \& Bernardini, C. (2005). Structure of the mitochondrial control region of the Eurasian Otter (Lutra lutra; Carnivora, Mustelidae): Patterns of genetic heterogeneity and implications for conservation of the species in Italy. Journal of Heredity, 96(4): 318-328. http://dx.doi.org/10.1093/jhered/esi037

Miyazono, F., Schneider, P.M., Metzger, R., Warnecke-Eberz, U., Baldus, S.E., Dienes, H.P., Aikou, T. \& Hoelscher, A.H. (2002). Mutations in the mitochondrial DNA D-Loop region occur frequently in adenocarcinoma in Barrett's esophagus. Oncogene, 21: 3780-3783. http://dx.doi.org/10.1038/sj.onc.1205532

Pereira, F., Carneiro, J. \& van Asch, B. (2010). A guide for mitochondrial DNA analysis in non-Human forensic investigations. Open Forensic Science Journal, 3: 33-44. http://dx.doi.org/10.2174/1874402801003020033

Pereira, L., van Asch, B. \& Amorim, A. (2004). Standardisation of nomenclature for dog mtDNA D-loop: a prerequisite for launching a Canis familiaris database. Forensic Science International, 141: 99-108. http://dx.doi.org/10.1016/j.forsciint.2003.12.014

Salas, A., Lareu, M.V. \& Carracedo, A. (2001). Heteroplasmy in mtDNA and the weight of evidence in forensic mtDNA analysis: A case report. International Journal of Legal Medicine, 114: 186-190. http://dx.doi.org/10.1007/s004140000164

Sambrook, J. \& Russell, D.W. (2001). Molecular cloning: A laboratory manual. (3rd ed.). Cold Spring Harbor Laboratory Press, Cold Spring Harbor, New York.

Sbisa, E., Tanzariello, F., Reyes, A., Pesole, G. \& Saccone, C. (1997). Mammalian mitochondrial D-loop region structural analysis: identification of new conserved sequences and their functional and evolutionary implications. Gene, 205(1-2): 125-140. http://dx.doi.org/10.1016/S0378-1119(97)00404-6

Tiedemann, R., Hardy, O., Vekemans, X. \& Milinkovitch, M.C. (2000). Higher impact of female than male migration on population structure in large mammals. Molecular Ecology, 9: 1159-1163. http://dx.doi.org/10.1046/j.1365-294x.2000.00975.x

Tsutsumi, H., Komuro, T., Mukoyama, R. \& Nogami, H. (2006). Hypervariable region structure and polymorphism of mtDNA from dental pulp and a family analysis. Journal of Oral Science, 48(3): 145-152. http://dx.doi.org/10.2334/josnusd.48.145

Wallace, D.C. (1994). Mitochondrial DNA sequence variation in human evolution and disease. Proceedings of the National Academy of Sciences, 91: 8739-8746. http://dx.doi.org/10.1073/pnas.91.19.8739

Witas, H.W. \& Zawicki, P. (2004). Mitochondrial DNA and human evolution: A review. Przeglad Antropologiczny - Anthropological Review, 67: 97-110. 
Table 1. Restriction morphs of HaeIII enzyme for mtDNA D-loop region and their frequencies

\begin{tabular}{c|l}
\hline Fragment length (bps) & Number of samples \\
\hline $109,435,480$ & $82(48.81 \%)$ \\
$109,365,550$ & $28(16.66 \%)$ \\
$109,405,510$ & $22(13.1 \%)$ \\
$35,109,400,480$ & $35(20.83 \%)$ \\
$109,365,435,480,550$ & $1(0.6 \%)$ (Heteroplasmy) \\
\hline Total & $\mathbf{1 6 8}$ \\
\hline
\end{tabular}

Table 2. Restriction morphs of $A l u \mathrm{I}$ enzyme for mtDNA D-loop region and their frequencies

\begin{tabular}{c|c}
\hline Fragment length (bps) & Number of samples \\
\hline & \\
$124,400,500$ & $81(48.21 \%)$ \\
$124,400,500$ & $28(16.66 \%)$ \\
$124,400,500$ & $22(13.1 \%)$ \\
$124,400,500$ & $35(20.83 \%)$ \\
$100,124,124,400,500,800$ & $2(1.2 \%)($ Heteroplasmy) \\
\hline Total & $\mathbf{1 6 8}$ \\
\hline
\end{tabular}

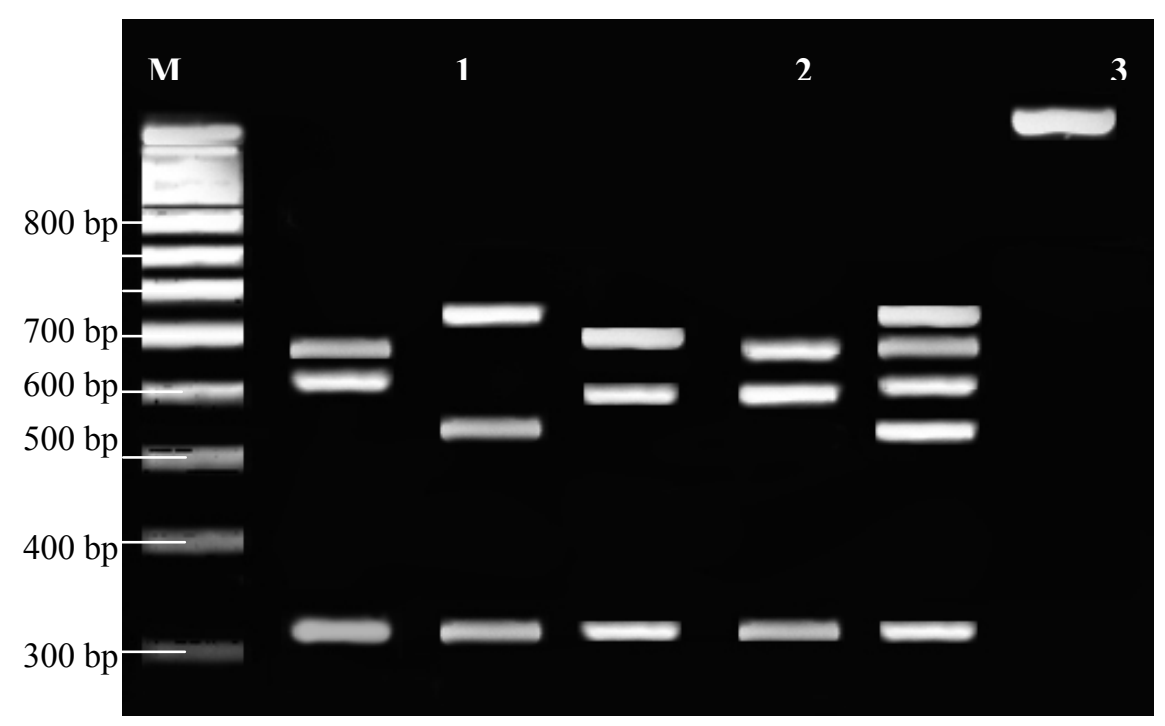

Figure 1. Digestion results of PCR products of mtDNA D-loop region with HaeIII enzyme (Line M is $100 \mathrm{bp}$ DNA ladder (Fermentas, Germany), line 1 is 109,435 and 480 bps, line 2 is 109, 365, 550 bps, line 3 is 109, 405, $510 \mathrm{bps}$, line 4 is 35, 109, 400, $480 \mathrm{bps}$, line 5 is 109, 365, 435, 480, and 550 bps (Heteroplasmy), and line 6 is PCR products or uncut fragment (1024 bp), respectively) 


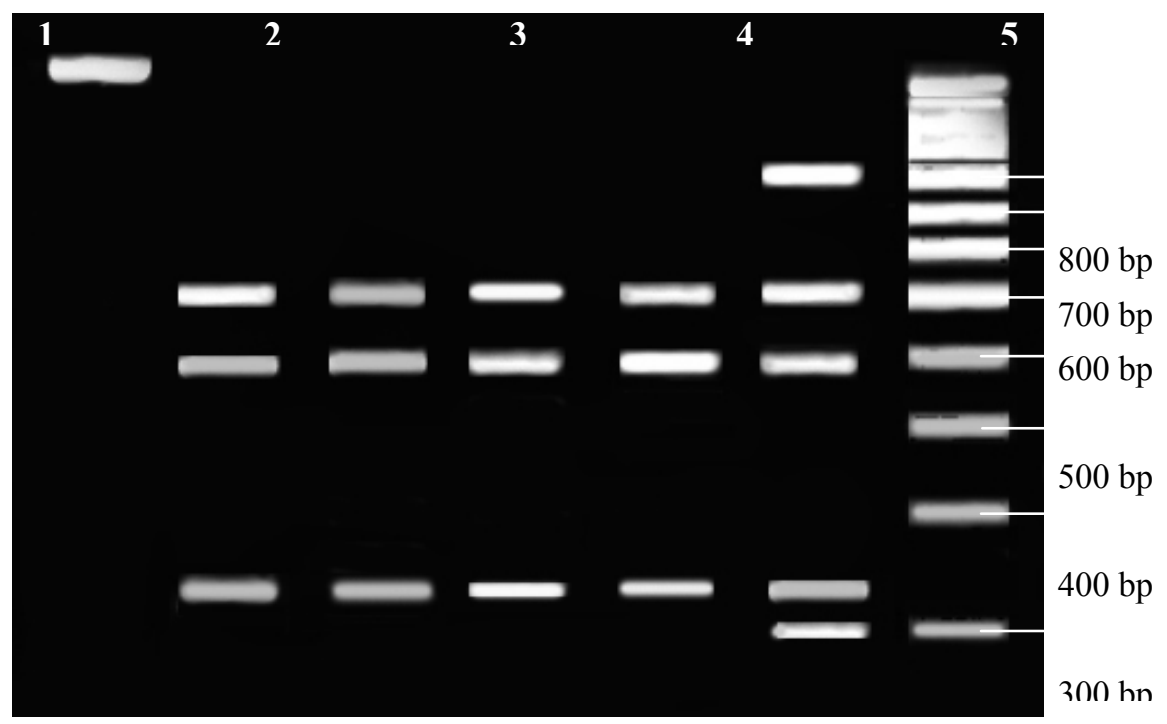

Figure 2. Digestion results of PCR products of mtDNA D-loop regions with AluI enzyme (Line 1 is PCR products or uncut fragment (1024 bp), line 2 is 124, 400, and $500 \mathrm{bps}$, line 3 is 124, 400, and $500 \mathrm{bps}$, line 4 is 124,400 , and $500 \mathrm{bps}$, line 5 is 124,400 , and $500 \mathrm{bps}$, line 6 is 100, 124, 124, 400, 500, and $800 \mathrm{bps}$ (Heteroplasmy), and line M is 100 bp DNA ladder (Fermentas, Germany), respectively) 